\title{
Hemorrhagic Complication of Pregnancy
}

National Cancer Institute

\section{Source}

National Cancer Institute. Hemorrhagic Complication of Pregnancy. NCI Thesaurus.

Code C35580.

Bleeding occurring during pregnancy. 